\title{
SELF-EDUCATION AND LIFELONG LEARNING
}

\author{
Oprea lonuț Mihai \\ PhD, Lect, University of Oradea, Romania, oprea_ionut_mihai@yahoo.com
}

\begin{abstract}
One of the most important elements of personality development lies outside the formal studies. The training period in the educational process is short, compared to the time spent outside it, during the life of an adult. For most adults, school is left behind, with the focus on work. In turn, jobs require continuous adaptation, but of different intensity and variability. Depending on the job selected, an adult who ends period of compulsory education, but also those who complete undergraduate studies, even post-graduate, face a matter of ability to learn to adapt to different environments which last a lifetime. The problem is even bigger, as studying in specialized environments involves excessively high expenses, which the vast majority of the population cannot afford. In this context, the solution could be guided self-education. Self-education is the process by which information, skills and new abilities are obtained, through one's own efforts, outside the institutionalized education system. The purpose of this study is to describe a number of elements necessary for self-education, to be conceptualized, organized, implemented and supported, not only during a short period of time and limited to a minimum number of purposes, but to be implemented as a long-term process. The principles described would be useful in the context of avoiding or resolving any cases, but also to maximize the results of the self-education process.
\end{abstract}

Keywords: self-education, educational process, skills, competencies.

\section{THE BASIC PRINCIPLE OF SELF-EDUCATION}

Education and self-education are two realities of two types of educational processes. The first is carried out in a formal, institutionalized framework, subject to the rigors and rules imposed through a system. The second is a method that takes place exclusively outside the institutionalized system (Pinnegar \& Russell, 1995), but which can take over methodologies and practices from the formal education. Also, self-education aims to create personal comfort through independence from the rules of the system, but still responding to needs within it. An important aspect, still not sufficiently addressed, is the inability of the institutionalized system to teach students (Whitehead, 2009), ie the future workforce, to develop skills that will help them in initiating and maintaining a process of self-education, which makes them independent, but much better prepared professionally (Gibbons \& Phillips, 1982).

\section{ELEMENTS OF SELF-EDUCATION}

Self-education always takes place outside the educational institutions. The role of the educational institutions would be to prepare and develop the skills and knowledge needed to initiate, support and develop selfeducation (Inc, 2014). Also, self-education takes place only when there is no personal obligation to learn and when education is not imposed by any authority, in any formal environment, according to any official curriculum. Self-education is an approach that takes place exclusively in relation to a person's free will, who autonomously defines the intention and purpose of the approach (Gibbons \& Phillips, 1982, pp. 70-71).

There is a substantial difference between formal education and self-education in terms of control over the act. In formal education, control resides in the system, institution and teacher. With the end of the educational cycles, the transition to self-education is made through a shock, due to the awareness of the 
need for self-control. For this reason, self-education is abandoned, limiting the possibility of obtaining major material and intellectual benefits (Barth, Ciobanu, 2017).

The main cause of failure is formal schooling, which does not prepare students to become self-taught, and the skills they learn are useful only in academia or in the specialized workplace. Becoming self-taught as a direct result of the education system is almost impossible. Not only initiation, but also support and especially the development of one's own self-education system requires both a correctly delimited goal (Shikati, 2018) and a high level of self-discipline. Both elements are necessary in order to be able to solve or avoid the possible problems that appeared during the approach. If purpose and self-discipline are important, an important role is also played by initiative. This element is the impetus to start the self-teaching process. The initiative is not only found at the beginning of the self-education process, but also throughout it, varying from one educational need to another. In the formal system, the teacher is the initiator of educational approaches, but does not develop the aptitude in students, which is why after the educational cycle, future employees may be unable to initiate personal educational approaches. Although teaching methods are implemented by teachers in the classroom, they are not explained to students, although, to a large extent, they would need these methods to be able to support and streamline self-education. The habit with the school environment does not allow students to observe the details of classroom management, but neither the efforts made to organize teaching materials, learning and teaching styles, but also the mechanisms behind an effective educational act. Self-education is also based on sustained efforts of organization and general management (Sagitova, 2014), which have to do, on a personal level, with how to solve possible inadvertences, which can thwarts or even stop the educational process.

A possible solution to the conflict lies in the efforts of a community, which could make various resources available to self-taught people, in a loan system, or for free. Satisfaction is an important element in the education process, remaining equally important for self-education. Formal education is restrictive and limited, while self-education requires more extensive resources and options (Pascariu, 2020).

Satisfaction of education on a personal level could be an important factor in organizing and maintaining selfeducation. Compared to the formal education system (Beckett, 1996), self-education is limited only by the purpose and imagination of the person involved, given that the result should be an improvement in the quality of life. School and education should not be separated from the daily life of the student, and selfeducation involves involvement in everyday life, systematic learning becoming a constant element in the life of the individual (Gibbons \& Phillips, 1982).

\section{PRACTICAL ELEMENTS}

The critique uttered towards the traditional education system also focuses on its practical level, which limits both the spirit of initiative and the purpose of education, dependence and the way of evaluation and selfevaluation. At the personal and systemic level, traditional education reduces its goal to the immediate needs of society, relying exclusively on the opinions of experts in certain fields, drastically reducing the role of the student in the interaction with the learned subject. Individuality can easily be reduced to a minimum necessary for a limited functioning within the broad framework of society.

The individual is reduced to the "element", not being cultivated as a "person". From this point of view, selfeducation, although it contains an element of individuality and self-determination, does not work exclusively in personal terms. The process requires independence, considered as the ability of a person to achieve his/her goals and function optimally in society. The process also requires interdependence, and the success of the process will also depend on how, through sustained effort, practices and relationships have been conducted with professionalism and mutual trust. These skills are learned, but not always in school. Selfeducation also involves the creation of a network, in which the parties involved can achieve various levels of cooperation (Gibbons \& Phillips, 1982).

Another important element of formal education is that of the attention paid for a limited period of time to a single subject of study. In schools, the attention is divided on various topics, for a limited period of time, of maximum 50 minutes. In the process of self-education, attention is given for longer periods of time, sometimes without a deadline, which can be beneficial for the learner, but also problematic, if the project is collaborative and limited by a completion period. Regardless of the situation, attention is distributed differently, and items of no interest, such as extra disciplines, are removed from the work field so that attention is focused on one at a time (Gibbons \& Phillips, 1982).

Formal education focuses learning outcomes not so much on practical elements as on assessment, which is usually a written exam. The evaluation method in self-education is by presenting the product or exercising the new skills or services offered. Assessments or self-assessments can generate a new interest, a new stage in the development of skills or a reorientation towards new skills and products. In essence, self- 
education assessment is about oneself and with previous results (Gibbons \& Phillips, 1982).

\section{FINAL CONSIDERATIONS}

Self-education can be a process and a skill that takes place strictly outside the institutions of formal education, if we consider it from the perspective of the final goal and the process of organization. However, this habit takes place, with limits, during the formal education process. In other words, all education has a component of self-education. The basic feature of self-education seems to be adaptability. Being self-taught means the ability to build a lifestyle that depends on services and products tailored to personal and community needs (Barth, 2019).

The efficiency of the self-education system can be implemented in several stages, but starting from within the formal education system. The first stage would be to move from teacher-centered to student-centered education. The working principle (A Cross-Cultural History of Self-Teaching - ProQuest, n.d.) of this method is relatively simple, related to the complexity of the act of self-education and requires a teacher to teach students how to select the materials to learn by themselves. The teacher does not provide the work material, but the selection method.

The second stage would consist in the transition from education centered to student, to self-education guided from the outside. The stage also takes place within the institutionalized education system, but the emphasis is on the overall image of society. However, the perspective is anchored in the studies in which it is involved in the system (Hilard, 2005), but giving a different meaning to the finality of this process. The third stage would consist in the transition from guided self-education to self-education, but fundamentally focused on achieving professional excellence. The third stage is the transition to adulthood, students being able to understand both the organization of the social system in which they live and also the ways to adapt to maximize the professionalism. The student who completes the last stage of the education process should be willing to begin the process of self-education (Gibbons \& Phillips, 1982).

A self-taught person advances in the knowledge of the object or subject of study, becoming a professional in its creation, maintenance, development and delivery to those who need it (Politics, Practices, and Possibilities of Open Educational Resources - ProQuest, n.d.). From this perspective, a self-taught person is by definition a person who excels in skills and has developed them, becoming useful to both himself and the community. The process of self-education is not limited to a certain age or a certain type of personality. The flexibility of the concept is applicable to almost any type of personality, being limited only by the personal awareness of one's own development possibilities (Gibbons \& Phillips, 1982).

\section{REFERENCE LIST}

Barth, K.M., (2019), The role of multicultural projects in the development of the personality of children with special educational needs, in "The role of intercultural communication in adapting ethnic groups to the European Union Social Space", edt. K.M Barth, M. Brie, D. Dărăbăneanu, I. Polgar, Lambert Academic Publishing, Ltd., pp. 307-315.

Barth, K., Ciobanu, N.R., (2017), Mass media influence upon personality development of children, in "Education and Applied Didactics", Vol. I, Issue 1, 2017, Publishing House of University of Oradea, pp. 7-25.

Beckett, R. G., (1996), Critical thinking and self-efficacy in autodidactic learning: The effects of program type, self-esteem, and program characteristics. Doctoral Dissertations, pp. 1-222.

Gibbons, M., Phillips, G. (1982). Self-Education: The Process of Life-Long Learning. Canadian Journal of Education / Revue Canadienne de l'éducation, 7(4), pp. 67-86. https://doi.org/10.2307/1494774

Hillard, C. (2005), Modernism and the Common Writer. The Historical Journal; Cambridge, 48(3), pp. 769787.

Inc, B. (2014), Never Stop Learning: How Self-Education Creates a Bullet-Proof Career, Adobe 99U. https://99u.adobe.com/articles/29995/never-stop-learning-how-self-education-creates-a-bullet-proofcareer

Pascariu C. C., (2020), Lifelong learning as a continuous self-education action, in Romanian Journal of School Psychology, Volume 13, Issue 25, Editor, Drugaș, M., Publishing House of University of Oradea, pp. 41-47. 
Pinnegar, S., Russell, T., (1995), Introduction: Self-Study and Living Educational Theory, Teacher Education Quarterly, 22(3), pp. 5-9.

ProQuest. (n.d.)., (2020), Politics, practices, and possibilities of open educational resources, from http://search.proquest.com/docview/1034609438/ECC8FE4F7AC84E0FPQ/11?accountid=136549

ProQuest. (n.d.). (2020), A Cross-Cultural History of Autodidacticism, from http://search.proquest.com/docview/897647198/ECC8FE4F7AC84E0FPQ/1 ?accountid=136549

Sagitova, R., (2014)., Students' Self-education: Learning to Learn Across the Lifespan, Procedia - Social and Behavioral Sciences, 152. https://doi.org/10.1016/j.sbspro.2014.09.194

Shikati, C., (2018), Self-Education: The key to living the life you want. Medium. https://medium.com/swlh/selfeducation-the-key-to-living-the-life-you-want-57af251c8e72

Whitehead, J., (2009), Self-study, Living Educational Theories, and the Generation of Educational Knowledge, Studying Teacher Education, 5, pp. 107-111.

https://doi.org/10.1080/17425960903306476. 